\title{
REVISITING THE REPRESENTATION THEOREM OF FINITE DISTRIBUTIVE LATTICES WITH PRINCIPAL CONGRUENCES. A PROOF-BY-PICTURE APPROACH
}

\author{
G. Grätzer AND H. LAKSER \\ Department of Mathematics \\ University of Manitoba \\ Winnipeg, MB R3T 2N2, Canada \\ e-mail: gratzer@me.com \\ hlakser@gmail.com
}

\begin{abstract}
A classical result of R.P. Dilworth states that every finite distributive lattice $D$ can be represented as the congruence lattice of a finite lattice $L$. A sharper form was published in G. Grätzer and E.T. Schmidt in 1962, adding the requirement that all congruences in $L$ be principal. Another variant, published in 1998 by the authors and E.T. Schmidt, constructs a planar semimodular lattice $L$. In this paper, we merge these two results: we construct $L$ as a planar semimodular lattice in which all congruences are principal. This paper relies on the techniques developed by the authors and E.T. Schmidt in the 1998 paper.
\end{abstract}

Keywords: principal congruence, finite distributive lattice.

2010 Mathematics Subject Classification: 06B10.

\section{REFERENCES}

[1] The Dilworth Theorems, Selected papers of Robert P. Dilworth. Edited by Kenneth P. Bogart, Ralph Freese, and Joseph P.S. Kung, Contemporary Mathematicians (Birkhäuser Boston, Inc., Boston, MA, 1990).

https://doi.org/10.1016/0001-8708(92)90026-h

[2] G. Grätzer, Standard ideals, Magyar Tud. Akad. Mat. Fiz. Oszt. Közl. 9 (1959) 81-97 (Hungarian).

[3] G. Grätzer, Lattice Theory: Foundation (Birkhäuser Verlag, Basel, 2011). 
[4] G. Grätzer, The order of principal congruences of a bounded lattice, Algebra Univ. 70 (2013) 95-105. https://doi.org/10.1007/s00012-013-0242-3

[5] G. Grätzer, The Congruences of a Finite Lattice, A "Proof-by-Picture" Approach, Second edition (Birkhäuser Verlag, Basel, 2016). https://doi.org/10.1007/0-817

[6] G. Grätzer and H. Lakser, Some preliminary results on the set of principal congruences of a finite lattice, Algebra Univ. 79 (2018), paper no. 21. https://doi.org/10.1007/s00012-018-0487-y

[7] G. Grätzer and H. Lakser, Minimal representations of a finite distributive lattice by principal congruences of a lattice, Acta Sci. Math. (Szeged) 85 (2019) 69-96. https://doi.org/10.14232/actasm-017-060-9

[8] G. Grätzer, H. Lakser and E.T. Schmidt, Congruence lattices of finite semimodular lattices, Canad. Math. Bull. 41 (1998) 290-297. https://doi.org/10.4153/cmb-1998-041-7

[9] G. Grätzer and E.T. Schmidt, Standard ideals in lattices, Acta Math. Acad. Sci. Hungar. 12 (1961) 17-86.

[10] G. Grätzer and E.T. Schmidt, On congruence lattices of lattices, Acta Math. Acad. Sci. Hungar. 13 (1962) 179-185.

Received 14 June 2020

Revised 31 October 2020

Accepted 31 October 2020 